ISSN: 1980-055X

Recebido em: 30/04/2010

Aceito para publicação em: 17/07/2010

\title{
PRECIPITAÇÃO NAS MESORREGIÕES DO ESTADO DO PARÁ: CLIMATOLOGIA, VARIABILIDADE E TENDÊNCIAS NAS ÚLTIMAS DÉCADAS (1978-2008)
}

\author{
Monik Fernandes de Albuquerque ${ }^{30}$ \\ Everaldo Barreiros de Souza ${ }^{31}$ \\ Maria do Carmo Felipe de Oliveira ${ }^{32}$ \\ José Augusto de Souza Júnior ${ }^{33}$
}

\begin{abstract}
RESUMO
Este trabalho utilizou dados de precipitação do período de 1978 a 2008 do banco de dados do projeto Rede Estadual de Previsão Climática e Hidrometeorologica do Pará (RPCH), com o objetivo de estudar a Climatologia, Variabilidade e Tendência da precipitação nas seis mesorregiões do estado do Pará, nas últimas décadas, considerando a escala anual, sazonal e mensal para analise climatologia e as médias anuais e sazonais para a análise da variabilidade e tendência da precipitação nas diferentes mesorregiões do Pará. Os resultados evidenciaram que, os maiores índices pluviométricos estão concentrados nas mesorregiões do Marajó, Metropolitana e Nordeste Paraense, com precipitação anual superior a $2000 \mathrm{~mm}$. Por outro lado, os menores valores anuais de precipitação, ficam reservados as mesorregiões Sudeste e Sudoeste do Pará. Observou-se claramente que o verão e o outono, seguramente, abrigam os meses mais chuvosos do estado. Em geral, a época chuvosa iniciase em dezembro e tem duração de cinco a seis meses, sendo o mês de março o que apresenta maior índice pluviométrico. A época menos chuvosa, onde predominam as chuvas de caráter convectivo, abrangem os demais meses do ano, sendo que o período de maior estiagem ocorre entre os meses de setembro e outubro. Observando as séries temporais da anomalia de precipitação padronizada anual, nota-se que a precipitação passou a apresentar anomalias negativas a partir da década de 90, para quase todas as mesorregiões do

\footnotetext{
${ }^{30}$ Graduando em Meteorologia - Universidade Federal do Pará - UFPA- monikalbuquerque@hotmail.com

${ }^{31}$ Professor Adjunto 04 - Faculdade de Meteorologia - Universidade Federal do Pará UFPA - everaldo@ufpa.br

32 Professora Adjunta 04 - Faculdade de Meteorologia - Universidade Federal do ParáUFPA- oliveiramaca@gmail.com

33 Mestrando em Meteorologia Agrícola - Universidade Federal de Viçosa - UFV jun086@gmail.com
} 
estado, ressaltando que apenas a mesorregião Nordeste do estado, não apresenta grande variação de anomalia. A análise individual sazonal pode-se notar uma inversão no padrão anual de anomalia, no trimestre de MAM, com altos índices de anomalia de precipitação após a década de 90, para todas as mesorregiões do Pará.

Palavra-chave: Climatologia. Tendência. Variabilidade. RPCH. Mesorregiões do Pará.

\section{ABSTRACT}

This study used precipitation data from the period of 1978 to 2008 from project RPCH (Pará's Hydrometeorological and Climate Prediction State Net) Project database with the objective to studying the climatology, variability and trend of precipitation in six meso-regions of the state of Pará, in the last decades, considering the annual, seasonal and monthly scales for climate analysis and the seasonal and annual averages for the analysis of variability and trend of rainfall in different Pará's meso-regions. The results showed that the highest rainfall are concentrated in the meso-regions of Marajó, Metropolitan and Northeast of Pará's State, with annual precipitation exceeding $2000 \mathrm{~mm}$. On the other hand, the lowest annual rainfall values, are reserved to the Southeast and Southwest meso-regions of Pará. It was clearly observed that summer and autumn, certainly, surely, have the rainiest months of the state. In general, the rainy season starts in December and lasts five to six months, where March is the month with highest rainfall index. The less rainy season, where dominates the convective rainfalls, cover the remaining months of the years, and the period of greatest drought occurs between the months of September and October. Watching the time series of annual standardized anomaly of rainfall, it is noted that the precipitation started to show negative anomalies from the decade of 90, for almost all meso-regions of the state, noting that only the northeast mesoregion of the state, do not show a wide variation of anomaly. The seasonal individual analyze can note a reversal in the annual pattern of abnormality in the MAM quarter, with high rates of precipitation anomaly after the decade of 90 for all meso-regions of Pará.

Key-word: Climatology. Trend. Variability. RPCH. Pará's Meso-Regions.

\section{INTRODUÇÃO}

A precipitação é um dos elementos climáticos mais importantes a ser analisado na região tropical, já que induz as características de outros elementos, tais como temperatura, umidade relativa e vento. A região amazônica apresenta uma precipitação média de aproximadamente $2.300 \mathrm{~mm} \mathrm{ano}^{-1}$ (FISCH et al. 1998).

O regime de precipitação na Amazônia não é homogêneo, apresenta variabilidade espacial e temporal condicionadas à interação de diferentes sistemas, sendo os principais: A Zona de Convergência Intertropical sobre o Oceano Atlântico Equatorial (MOLION, 1987; MOLION; KOUSKY, 1985; ROCHA, 
1991); a atividade da Alta da Bolívia que forma-se durante o verão do Hemisfério Sul (KOUSKY E KAYANO, 1981; MOLION, 1993); as penetrações pronunciadas de sistemas frontais que organizam e intensificam a Convecção Tropical principalmente sobre a porção centro-sul da Amazônia (KOUSKY; FERREIRA, 1981; VIRJI ;KOUSKY, 1983; OLIVEIRA, 1986); as Linhas de Instabilidade (CAVALCANTI ;KOUSKY, 1983; COHEN, 1989); e as manifestações de sistemas de tempo de meso e escala localizada (células ou aglomerados de cumulunimbus) que comumente se originam devido a aquecimento da superfície pela radiação solar incidente.

A maior parte dos estados da Amazônia apresenta seu período chuvoso durante os meses de outubro a maio. Considerando a média da chuva acumulada nestes meses, observam-se valores entre $600 \mathrm{~mm}$ e $2100 \mathrm{~mm}$, com máximos principais sobre uma grande região que engloba a porção oeste, centro e sul (Amazonas, Acre, Rondônia, Mato Grosso, Tocantins e sul do Pará) e outra na porção oriental (que inclui o sul do Amapá, leste do Pará e norte do Maranhão) (FIGUEROA; NOBRE,1990).

O período seco em grande parte da Amazônia ocorre durante os meses de junho, julho e agosto. Este período caracteriza-se pela baixa pluviosidade (chuvas abaixo de $50 \mathrm{~mm} / \mathrm{mês}$ ) e longos períodos de estiagem, as quais atingem principalmente o Acre, Rondônia, Mato Grosso, Tocantins, centro sul do Maranhão, e sul do Amazonas e do Pará. A chuva neste período ocorre em forma de pancadas isoladas e em áreas esparsas (SOUZA; AMBRIZZI, 2003)

\subsection{OBJETIVO GERAL}

Com base nos dados de precipitação do banco climatológico do projeto Rede Estadual de Previsão Climática e Hidrometeorológica do Pará (RPCH), uma série de dados de precipitação do período de 1978 a 2008, o objetivo geral deste trabalho é estudar a climatologia e a variabilidade da precipitação observada nas mesorregiões do Estado do Pará nas últimas décadas (19782008).

\subsection{OBJETIVOS ESPECÍFICOS}

- Calcular e analisar os aspectos climatológicos da precipitação representativa das diferentes mesorregiões do Pará considerando as escalas anual, sazonal e mensal.

- Analisar a variabilidade e tendência temporal da precipitação representativa das diferentes mesorregiões do Pará considerando as médias anuais e as médias sazonais.

\section{MATERIAL E MÉTODOS}

\subsection{DADOS}

Este trabalho abordou os totais mensais de precipitação para um conjunto de 150 estações meteorológicas de superfície distribuídas sobre a Amazônia Oriental (Figura 1). 


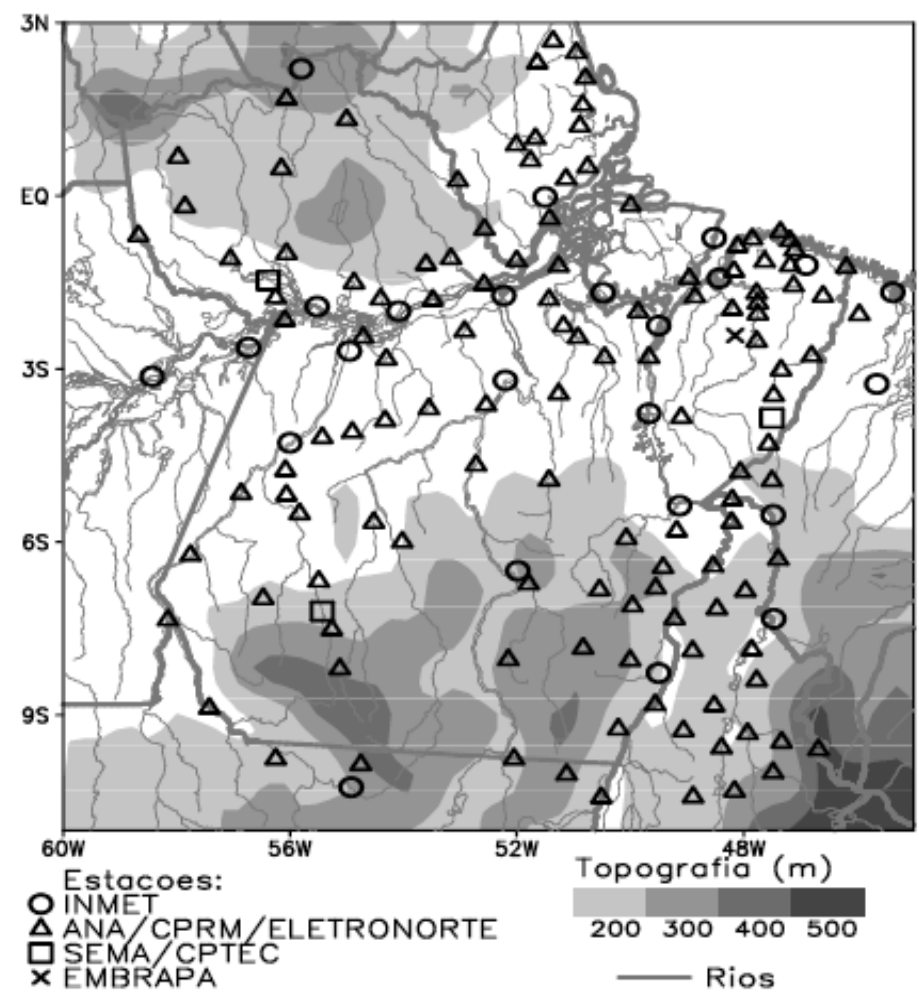

Figura 1. Localização das estações pluviométricas sobre o estado do Pará usadas para gerar a climatologia da precipitação da Rede de Previsão Climática e Hidrometeorológica (RPCH).

Fonte: Lopes (2009).

Com ênfase naquelas estações instaladas no estado do Pará e sua vizinhança, foram analisados trinta e um anos de registros, compreendendo o período de 1978 a 2008. Os registros meteorológicos considerados envolveram dados da Empresa Brasileira de Pesquisa Agropecuária (EMBRAPA), da Secretaria Estadual de Meio Ambiente (SEMA-PA) que trabalha em parceria com - Centro de Previsão do Tempo e Estudos Climáticos (CPTEC), do Instituto Nacional de Meteorologia (INMET) e da Agência Nacional de Águas (ANA), sendo que as estações da ANA são operadas pela Companhia de Pesquisa de Recursos Minerais (CPRM) e Centrais Elétricas do Norte do Brasil (Eletronorte). Esta base de dados, devidamente integrada, passou a constituir o novo banco climatológico do projeto Rede Estadual de Previsão Climática e Hidrometeorológica do Pará (RPCH). Conforme Lopes (2009), este novo conjunto de dados foi submetido a um rigoroso controle de qualidade, de acordo com os critérios apresentados em Higgins et al. (2000), aplicando-se técnicas que permitiram excluir as informações duvidosas, errôneas e omissas, levandose em consideração o desvio padrão superior a três vezes o valor médio. Assim, selecionaram-se apenas as estações cujos registros continham índice inferior a $5 \%$ de dados faltantes. As falhas, por sua vez, foram interpoladas, utilizando-se para tal os dados de estações próximas. A fim de obter um conjunto de dados de precipitação regional em pontos de grade no domínio do Pará, foi empregada 
a interpolação espacial (utilizando o método do inverso das distâncias ao quadrado) dos dados coletados de estações meteorológicas/hidrometeorológicas para uma grade regular com resolução de $0.27^{\circ}$ latitude $\times 0.27^{\circ}$ longitude. Lopes (2009) realizou uma extensa análise estatística de comparação da base RPCH com outros conjuntos de dados de precipitação e obteve resultados consistentes de que a precipitação $\mathrm{RPCH}$ representa muito bem as características regionais da pluviometria na Amazônia oriental.

\subsection{METODOLOGIA}

\section{Divisão em Mesorregiões:}

Segundo o IBGE as Mesorregiões Geográficas são conjuntos de municípios contíguos, pertencentes à mesma Unidade da Federação, que apresentam formas de organização do espaço geográfico definidas pelas seguintes dimensões: o processo social, como determinante; o quadro natural, como condicionante; e a rede de comunicação e de lugares, como elemento de articulação espacial.

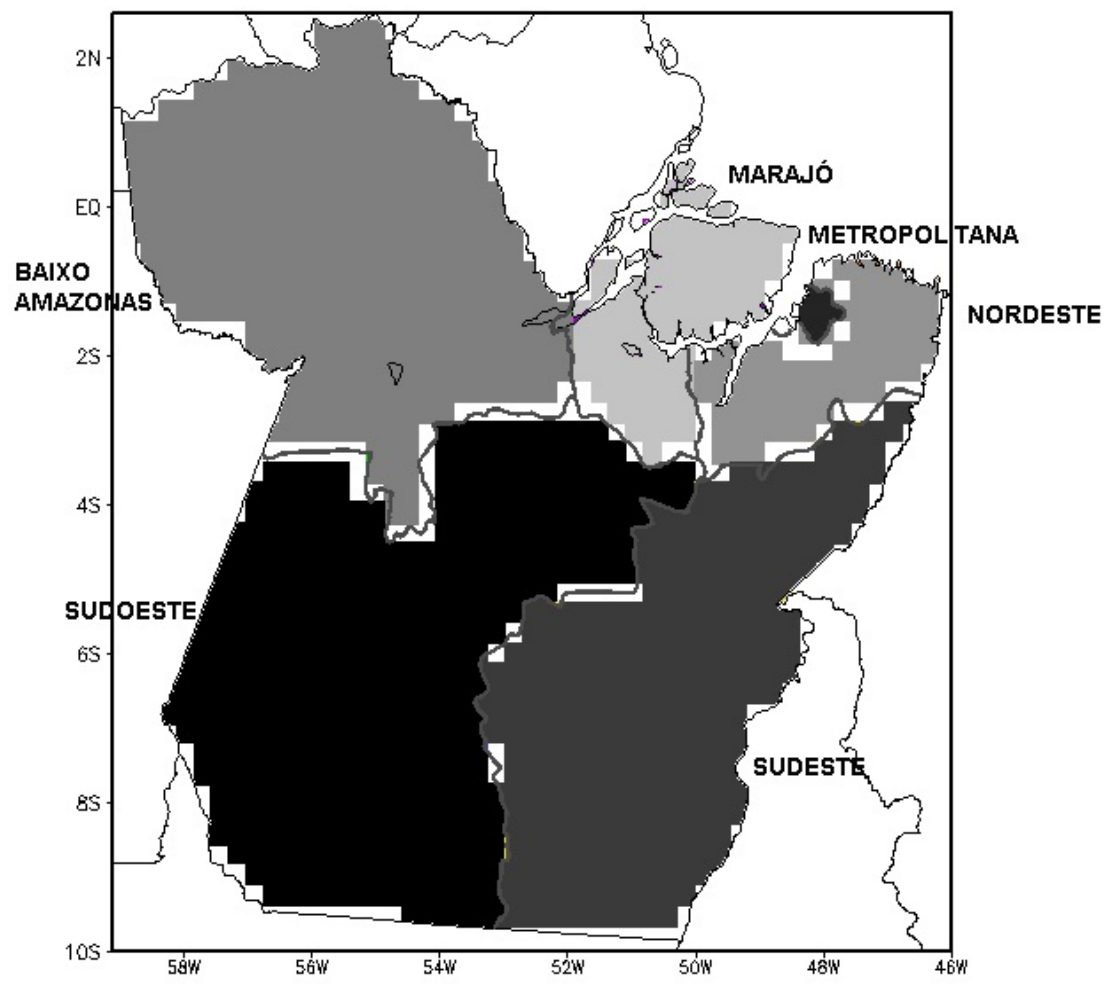

Figura 2. Mapa das seis mesorregiões geográficas do Estado do Pará.

Essas três dimensões possibilitam que o espaço delimitado como mesorregião tenha uma identidade regional. Esta identidade é uma realidade construída ao longo do tempo pela sociedade que aí se formou. Para o IBGE esses "recortes" visam traduzir, ainda que de maneira sintética, as diferenças 
na organização do território nacional quanto às questões sociais e políticas e possibilitam que o espaço delimitado como mesorregião tenha uma identidade regional específica.

A partir desses conceitos, o IBGE criou seis Mesorregiões Geográficas no Estado do Pará: Mesorregião Geográfica do Baixo Amazonas; Mesorregião Geográfica de Marajó; Mesorregião Geográfica Metropolitana de Belém; Mesorregião Geográfica do Nordeste Paraense; Mesorregião Geográfica do Sudoeste Paraense; e Mesorregião Geográfica do Sudeste Paraense.

- Média Climatológica:

A média climatológica é obtida pelo cálculo da média aritmética que é a mais importante mensuração numérica descritiva. Como medida de tendência central, trata-se do valor mais representativo de um conjunto de dados, isto é, seu ponto de equilíbrio.

- Reta de Tendência Linear:

Uma linha de tendência linear é uma linha reta de melhor ajuste usada com conjuntos de dados lineares simples. Seus dados serão lineares se o padrão nos pontos de dados se parecer com uma linha. Uma linha de tendência linear geralmente mostra que algo está aumentando ou diminuindo com uma taxa fixa.

- Variabilidade e Tendência Climática:

Define-se a variabilidade climática como uma variação das condições climáticas em torno da média climatológica. Já anomalia climática refere-se a uma flutuação extrema de um elemento em uma série climatológica, com desvios acentuados do padrão observado de variabilidade.

Neste trabalho utiliza-se a anomalia padronizada dada por:

$\mathrm{AP}=$ (valor observado - média climatológica) / desvio padrão

\section{RESULTADOS}

\subsection{Climatologia de PRECIPITAÇÃo 3.1.1. Climatologia Anual}

A distribuição da precipitação média anual no Estado do Pará, baseado nos dados da RPCH, está ilustrada na Figura 3. Observa-se que os maiores índices estão concentrados no Nordeste paraense, com precipitação superior a 2000 mm, englobando as mesorregiões do Marajó, Metropolitana de Belém e Nordeste Paraense. Destaca-se que a mesorregião Metropolitana de Belém é que apresenta o maior índice pluviométrico do Estado do Pará. O fato do alto índice pluviométrico está concentrado na região nordeste se deve a influência de sistemas de grande-escala como a ZCIT, forte convecção local, aglomerados de Cumulunimbus e por estar localizada às proximidades de áreas litorâneas. Por outro lado, os menores valores de precipitação, ficam reservados as mesorregiões Sudeste do estado, com valores inferiores a $1900 \mathrm{~mm}$. As 
mesorregiões do Baixo Amazonas e Sudoeste possuem precipitações anuais bem próximas, com valores de 2035 e 2030 mm, respectivamente.

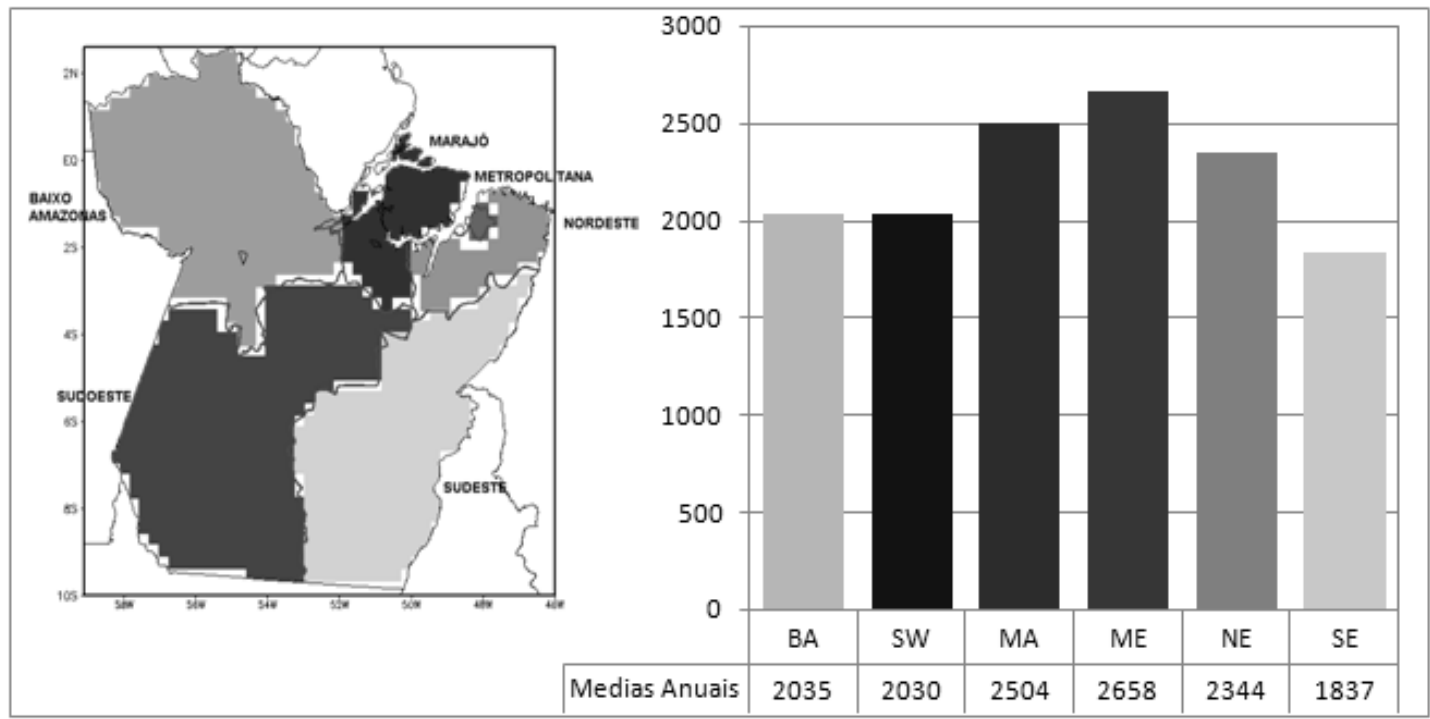

Figura 3. Médias climatológicas da precipitação anual (média 1978-2008) representativas das mesorregiões do Pará. Unidade: mm.

\subsubsection{Climatologia Sazonal}

Conforme Lopes (2009) convém analisar também a climatologia sazonal da precipitação, já que um fenômeno climático ou a combinação de fenômenos podem estar presente durante alguns meses do ano, provocando variações de maneira que a média anual não evidencia, necessariamente, o comportamento anômalo durante um determinado mês(es) ou estação(ões).

A Figura 4 mostra a climatologia sazonal da precipitação nas mesorregiões do Pará durante os períodos de verão (DJF), outono (MAM), inverno (JJA) e primavera (SON). Algumas diferenças intra-regionais podem ser percebidas quando se analisa a evolução da chuva por estação do ano. Claramente observa-se em todas as mesorregiões que o período chuvoso ocorre durante os períodos de verão e outono, enquanto que o período seco ou menos chuvoso ocorre durante os períodos de inverno e primavera.

Com relação aos extremos mínimos de chuva, observa-se que as regiões do Baixo Amazonas e Sudeste apresentam os menores valores sazonais, em torno de 85 e $130 \mathrm{~mm}$, se processando nos meses do inverno. Já os extremos máximos de chuva são observados nas regiões do Nordeste, Metropolitana e Marajó, com valores em torno de 1061, 1084 e 1091, durante o outono.

Com relação à evolução da chuva sazonal, verifica-se em todas as mesorregiões a ocorrência de uma transição muito brusca do período chuvoso para o período seco, ou seja, do outono para o inverno, com diminuição drástica dos valores de precipitação que passam de $600-1100 \mathrm{~mm}$ para $100-400 \mathrm{~mm}$, ou seja, diminuição em torno de 500 a 700 mm. Da mesma forma, mas não de maneira muito pronunciada, verifica-se em todas as mesorregiões que a transição do período seco para o período chuvoso se processa da primavera 
para o verão, com um aumento dos valores de chuva sazonal, que passam de 200-400 mm para 500-800 mm, ou seja, aumento em torno de 300 a $400 \mathrm{~mm}$.

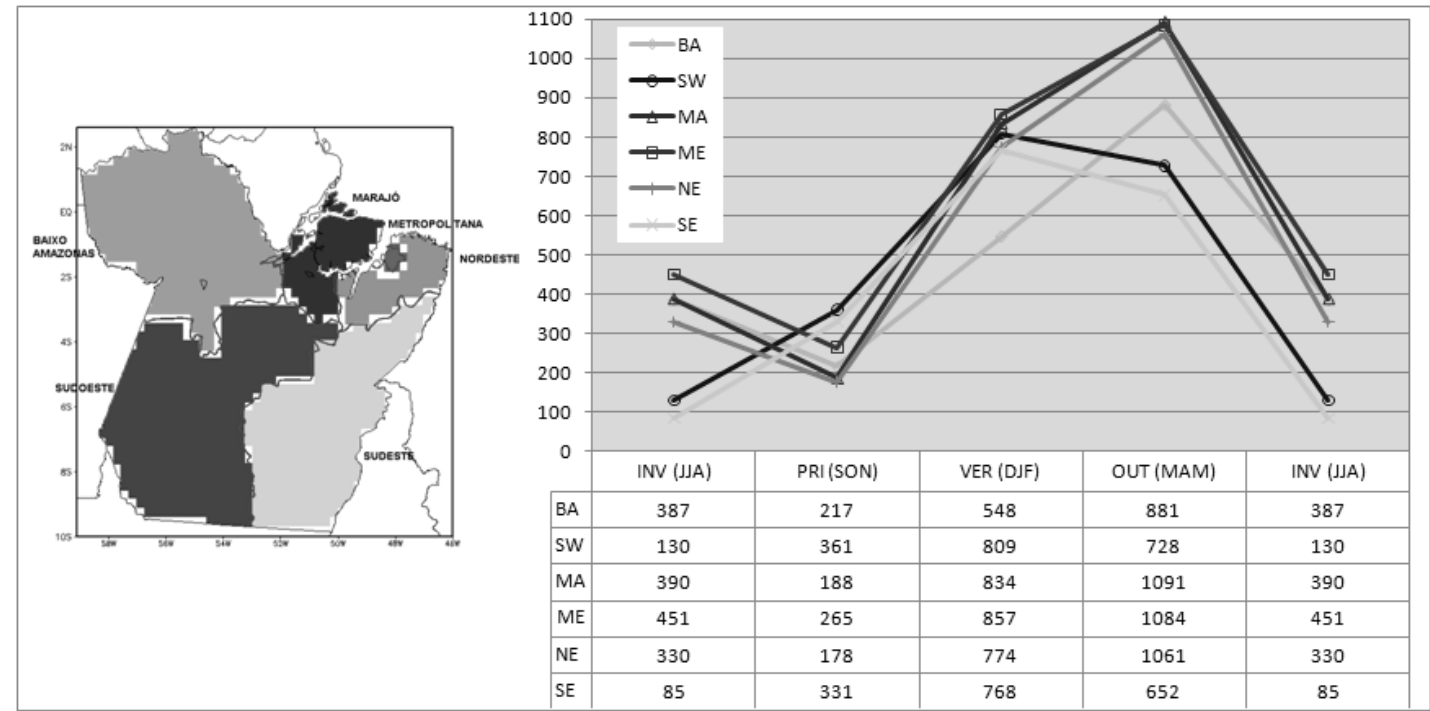

Figura 4. Médias climatológicas da precipitação sazonal (média 1978-2008) representativas das mesorregiões do Pará para as estações de inverno (INV JJA), primavera (PRI - SON), verão (VER - DJF) e outono (OUT - MAM). Unidade: $\mathrm{mm}$.

\subsubsection{Climatologia Mensal}

O Estado do Pará recebe precipitação praticamente durante todo o ano, com chuvas mais abundantes nos meses do verão e outono, mas também com pluviosidade considerável nos meses de inverno e primavera. Este fato é mostrado na Figura 5 contendo a evolução da chuva mensal de janeiro a dezembro para as mesorregiões do Pará.

Em geral, a época chuvosa inicia-se em dezembro e tem duração de cinco a seis meses, sendo o mês de Março mais chuvoso em todas as mesorregiões, exceto no Baixo Amazonas que é o mês de Abril, fato que é justificado pela intensificação dos efeitos locais associados à presença da ZCIT. A época menos chuvosa, onde predominam as chuvas de caráter convectivo na forma de pancadas de chuvas isoladas, abrangem os demais meses do ano, sendo que o período de menor precipitação mensal climatológica ocorre entre os meses de setembro e outubro em todas as mesorregiões, exceto para o Sudeste e Sudoeste que é entre Agosto e Setembro.

Observa-se na Figura 5, que o ciclo anual, ou seja, a evolução da precipitação climatológica mês a mês ao longo do ano é bem definido. O ciclo anual da precipitação no Estado é fortemente modulado pela marcha da ZCIT, causando os trimestres mais chuvosos de março, abril, maio (MAM) e dezembro, janeiro, fevereiro (DJF); e os menos chuvosos de setembro, outubro, novembro (SON) e junho, julho, agosto (JJA).

Destaca-se o máximo de precipitação no nordeste do estado, onde estão localizadas as mesorregiões do Marajó, Metropolitana de Belém e a mesorregião 
Nordeste paraense, com valores acumulados de precipitação acima de $400 \mathrm{~mm}$ no mês mais chuvoso do ano (Março), valores elevados em comparação as outras mesorregiões do estado. Já no mês de outubro/setembro observam-se os menores índices pluviométricos do ano para as mesorregiões do Nordeste do estado.
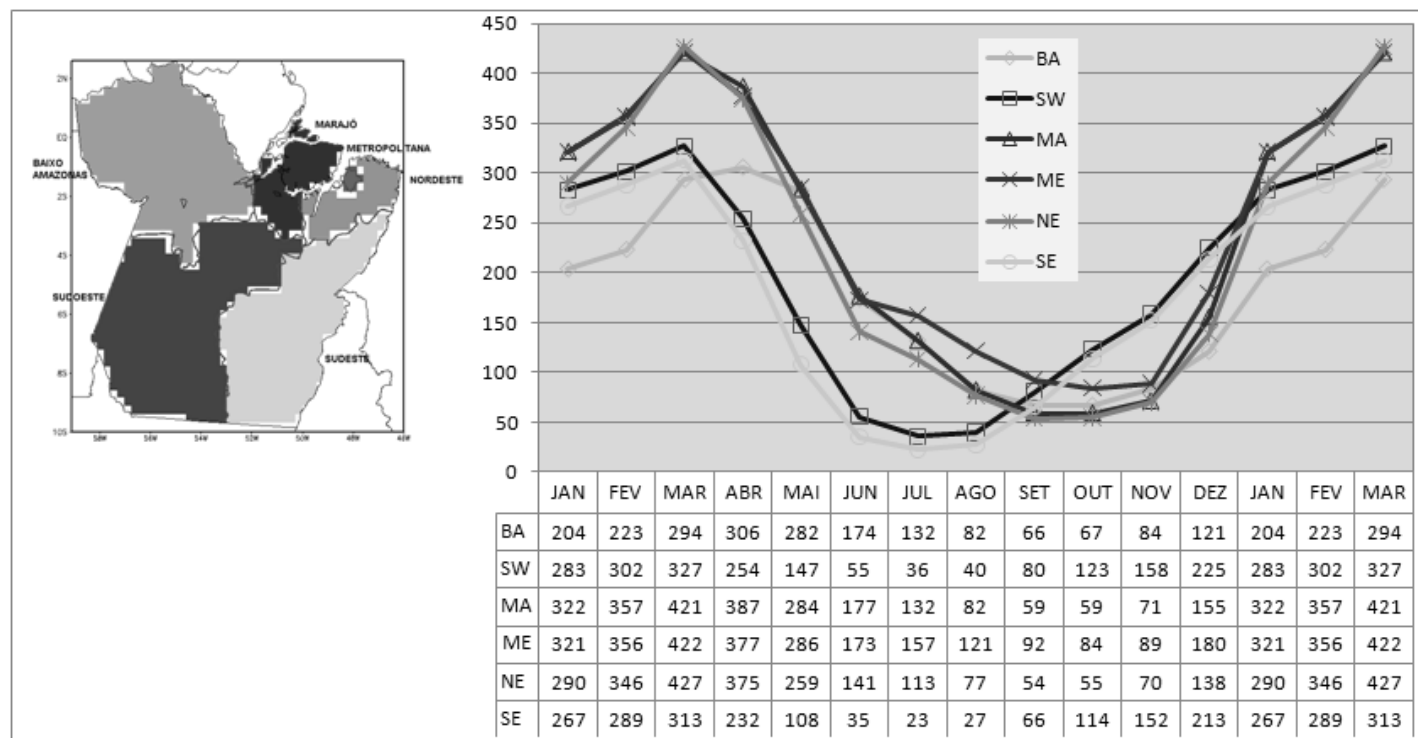

Figura 5. Médias climatológicas da precipitação mensal (média 1978-2008) representativas das mesorregiões do Pará para os meses de janeiro a dezembro. Unidade: $\mathrm{mm}$.

Para as mesorregiões Sudeste e Sudoeste do Estado, observa-se que a partir do mês de outubro, inicia-se o período chuvoso, com cerca de $100 \mathrm{~mm}$, tais valores aumentam no decorrer dos meses, até meados de maio, onde a região encontra seus maiores valores de precipitação, alcançando cerca de 350 $\mathrm{mm}$. Esse comportamento se dá por influência de episódios da ZCAS e seguida da atuação da ZCIT, que se encontra mais ao Sul do Pará nos meses de verão, causando assim os máximos índices de precipitação nas duas mesorregiões do Estado. No mês de Abril podemos observar que o índice de precipitação começa a diminuir, dando inicio a época menos chuvosa das mesorregiões localizadas ao Sul do Pará, presenciando os menores valores de precipitação sob a região, com mínimas chegando a $20 \mathrm{~mm}$ no mês de julho. O trimestre de Junho, Julho e Agosto apresenta-se como o período mais seco do ano.

\subsection{VARIABILIDADE E TENDÊNCIA DA PRECIPITAÇÃO}

\subsubsection{Precipitação Anual}

A Figura 6 mostra as séries de precipitação total anual, no período de 1978 a 2008, das mesorregiões do Estado do Pará. Nota-se que a precipitação apresenta comportamento similar nas seis mesorregiões. Com os menores índices de precipitação nas mesorregiões do Sudeste, Sudoeste e Baixo Amazonas, enquanto que os maiores índices de precipitação ocorrem no 
nordeste do estado, onde se localizam as mesorregiões do Marajó, Nordeste e Metropolitana.

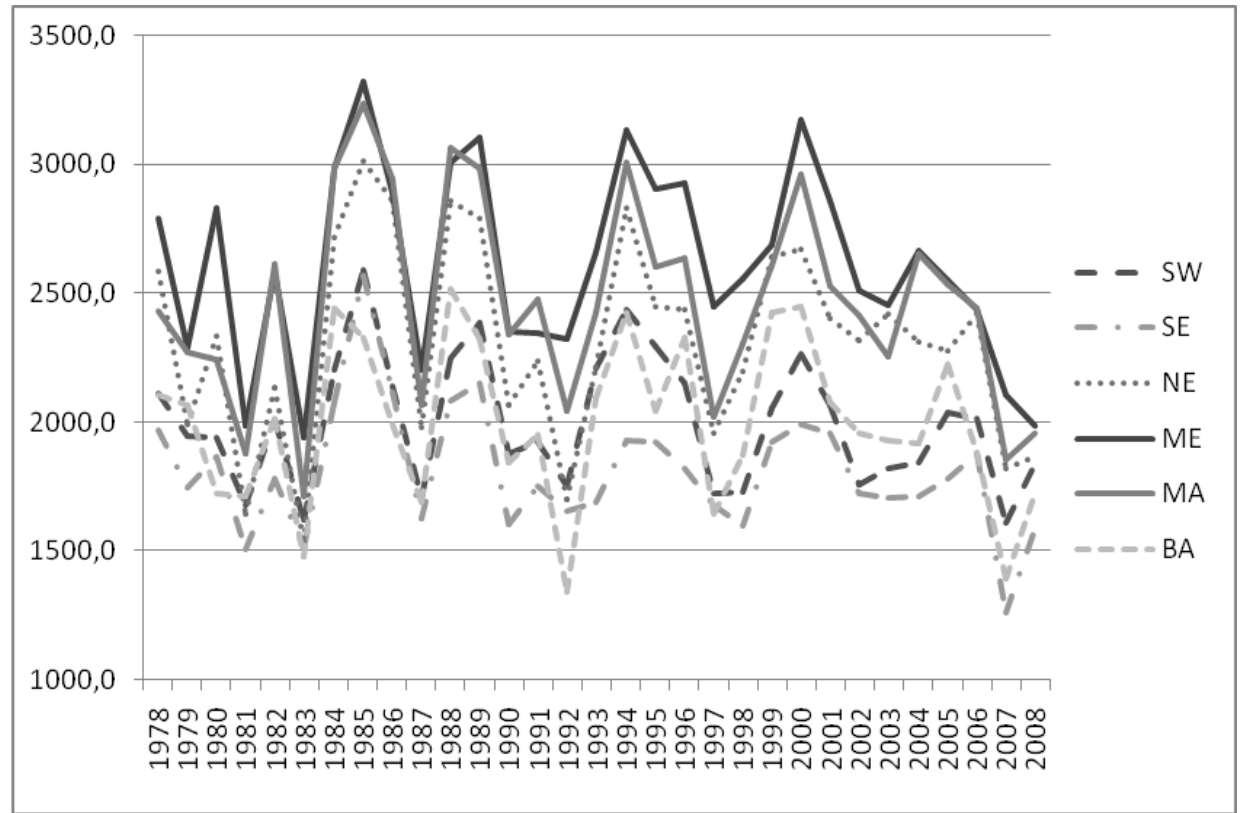

Figura 6. Séries temporais da precipitação total anual nas mesorregiões do Pará. Unidade: mm.

Analisando a série ano a ano, constata-se que nos anos de 2007 e 1983 ocorreram os menores valores de precipitação nas seis mesorregiões do Estado, ressaltando as mesorregiões do Sudeste, Sudoeste e Baixo Amazonas que apresentam sempre valores inferiores aos das demais mesorregiões. Já os maiores índices de precipitação foram registrados em 1985, nas mesorregiões do Marajó, Nordeste e Metropolitana de Belém. Nota-se que as três mesorregiões apresentam valores aproximados durantes toda à série de dados, entre as três mesorregiões a Nordeste paraense apresenta os menores índices de precipitação, enquanto que a mesorregião Metropolitana de Belém apresenta os maiores valores de precipitação da série de dados.

Já na analise das séries temporais da anomalia de precipitação padronizada anual, observou-se que a mesorregião Sudeste Paraense foi a mesorregião que apresentou mais significativo desvio de anomalia positivo, até o final da década de 90, com elevados índices de precipitação. Nota-se que entre os anos de 1990 e 1993 o comportamento do índice de precipitação foi razoavelmente dentro da normalidade, sem significantes anomalias de precipitação durante o período. Por outro lado, após o ano de 1993/1994 os desvios de anomalias tornaram-se negativos, com anomalias muito negativas para a mesorregião do Sudeste do estado.

Em geral, evidencia-se uma tendência de diminuição das anomalias de chuva anual, com a tendência mais pronunciada para a mesorregião do Sudeste Paraense, com $\mathrm{R}^{2}=0,073$. 


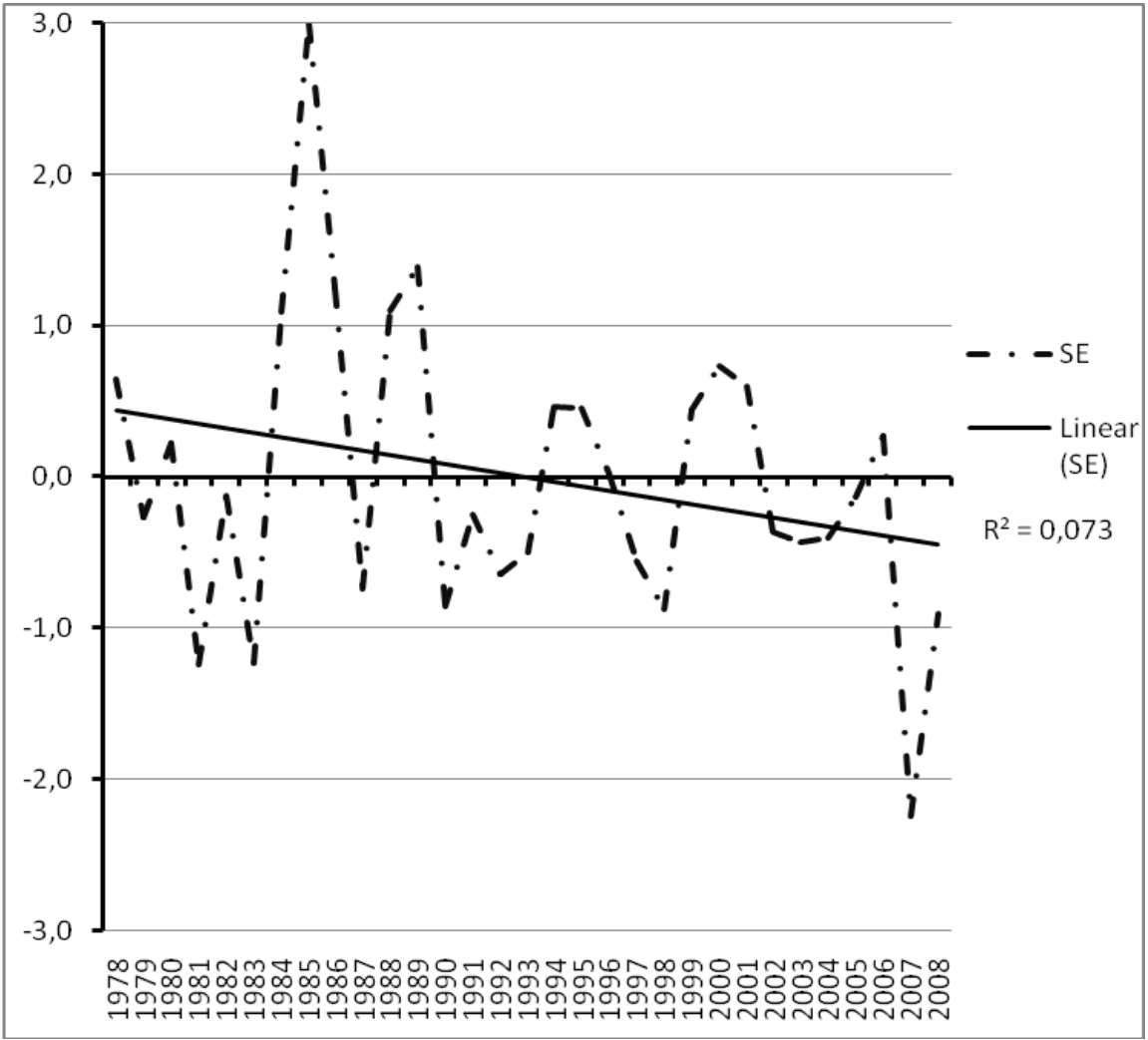

Figura 7. Séries temporais da anomalia de precipitação padronizada anual nas mesorregiões do Pará. Unidade: desvio padrão.

\subsubsection{Precipitação Sazonal}

Na secção anterior ficou evidente que em geral há uma tendência negativa (diminuição) da chuva nas mesorregiões do Pará. Entretanto, será que existe alguma sazonalidade embutida nesta tendência anual? Para responder esta pergunta, é conveniente analisar as séries temporais e tendência separadamente para cada estação do ano.

\subsubsection{Trimestre DJF (Verão)}

$\mathrm{Na}$ analise sazonal das séries temporais de precipitação para o trimestre de DJF, nota-se acentuados índices de precipitação em todas as mesorregiões do estado, caracterizando o inicio do período chuvoso determinado pela chegada da ZCIT que coincide com a época de maior ocorrência da ZCAS e AB que influenciam principalmente as mesorregiões Sudeste e Sudoeste do estado. Destacam-se os anos de 1979, que apresentou alto índice pluviométrico na mesorregião Metropolitana em contra partida o ano de 1982 apresentou o menor índice de precipitação da série.

A Figura 9 mostra a anomalia de precipitação para o trimestre de DJF (verão), notou-se que a mesorregião Sudoeste Paraense foi a que apresentou os maiores índices de anomalias positivas durante o período que vai de 1978 até 
1990, com destaque para o ano de 1984/1985 que apresentou o maior índice pluviométrico da série. Nota-se uma tendência negativa (diminuição) de chuva sazonal do verão principalmente para a mesorregião Sudoeste, com $R^{2}=0,0463$.

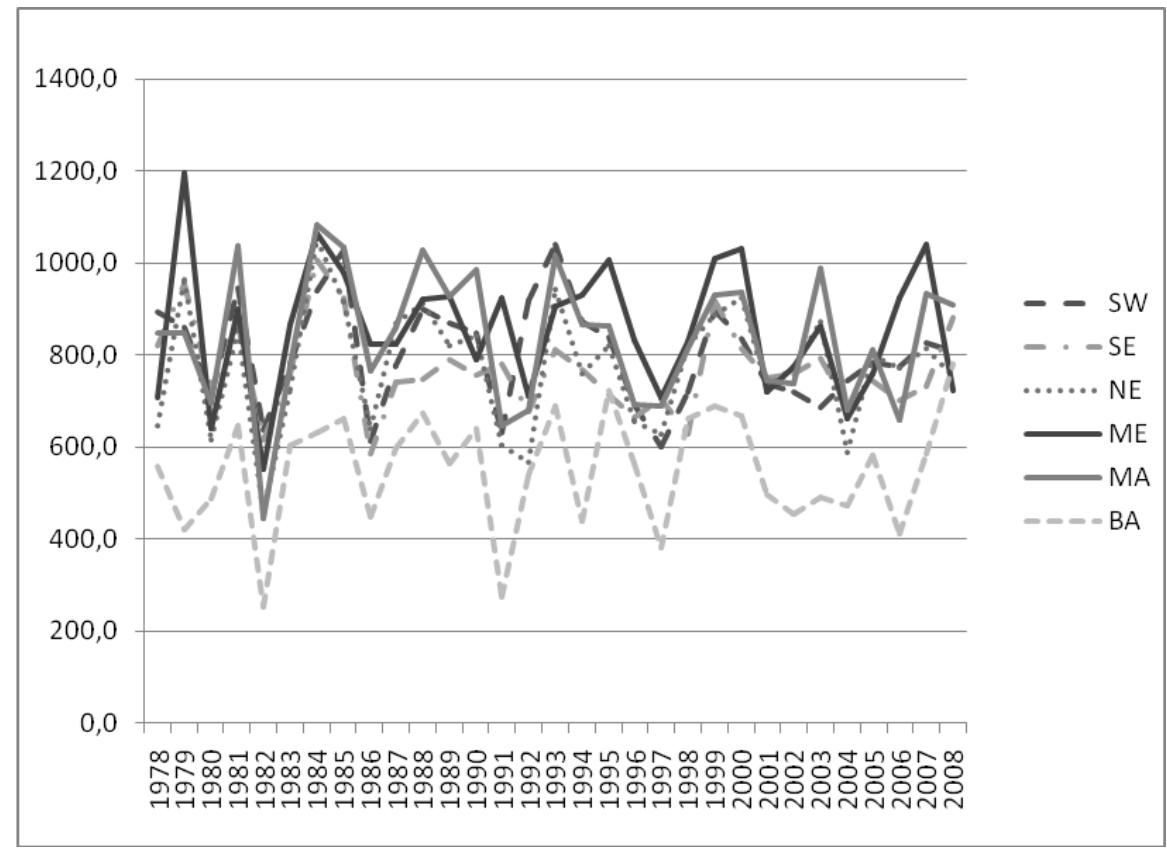

Figura 8. Séries temporais da precipitação total sazonal para DJF (verão) nas mesorregiões do Pará. Unidade: mm.

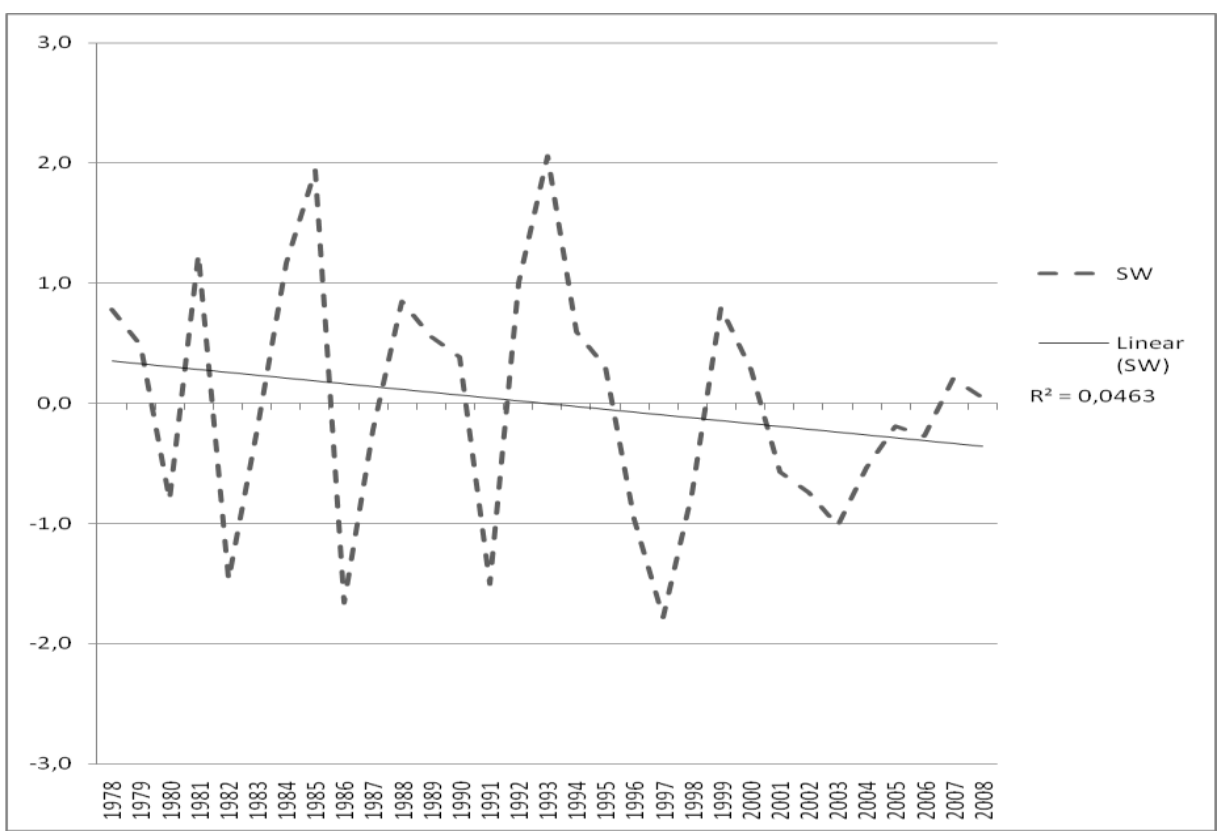

Figura 9. Séries temporais da anomalia de precipitação padronizada sazonal para DJF (verão) nas mesorregiões do Pará. Unidade: desvio padrão. 


\subsubsection{Trimestre MAM (Outono)}

Analisando as séries temporais da precipitação total sazonal para o Outono (MAM), nota-se que as mesorregiões localizadas no nordeste paraense são as que apresentam maior índice pluviométrico, entre as demais mesorregiões do estado. Este alto índice de precipitação está associado à posição da ZCIT que se desloca mais ao HN neste período. Observa-se nos anos de 1984 a 1986; 1999 a 2000; 1994 a 1996, índices de precipitação acima do normal em grande parte das mesorregiões do estado, estes picos de precipitação estão associados ao fenômeno La Niña, que induzida pela ZCIT favorece a ocorrência de precipitação acima do normal em grande parte da Amazônia Oriental. Nas mesorregiões localizadas ao sul do estado (mesorregião Sudeste e Sudoeste) apresentam menores índices pluviométricos, pelo retraimento dos episódios de ZCAS.

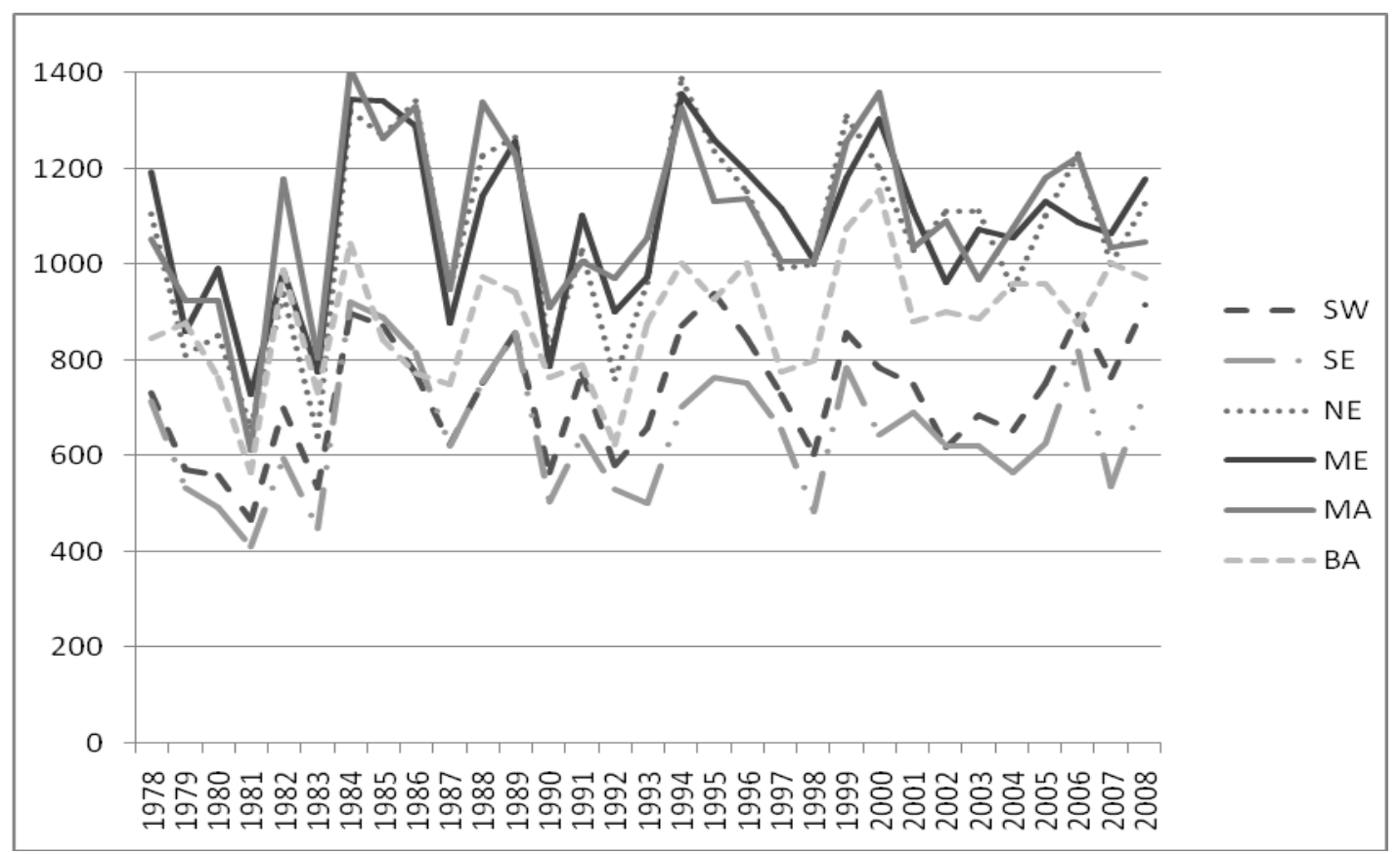

Figura 10. Séries temporais da precipitação total sazonal para MAM (outono) nas mesorregiões do Pará. Unidade: $\mathrm{mm}$.

Analisando as anomalias de precipitação no trimestre MAM (figura 11), nota-se que há uma inversão no padrão anual de anomalia. Observa-se agora, que altos índices de anomalia negativa concentram-se entre os anos de 1978 até o inicio da década de 90, anomalia essa observada principalmente na mesorregião do Baixo Amazonas. Que após o inicio dos anos 1990 apresenta elevado índice de anomalia positiva, observando que a mesorregião que antes apresentava índices negativos de anomalia agora apresenta os maiores valores de anomalia positiva da série para o trimestre.

Em geral, nota-se principalmente, uma tendência positiva generalizada de chuva sazonal de outono para a mesorregião do Baixo Amazonas do Pará, com $\mathrm{R}^{2}=0,166$. 


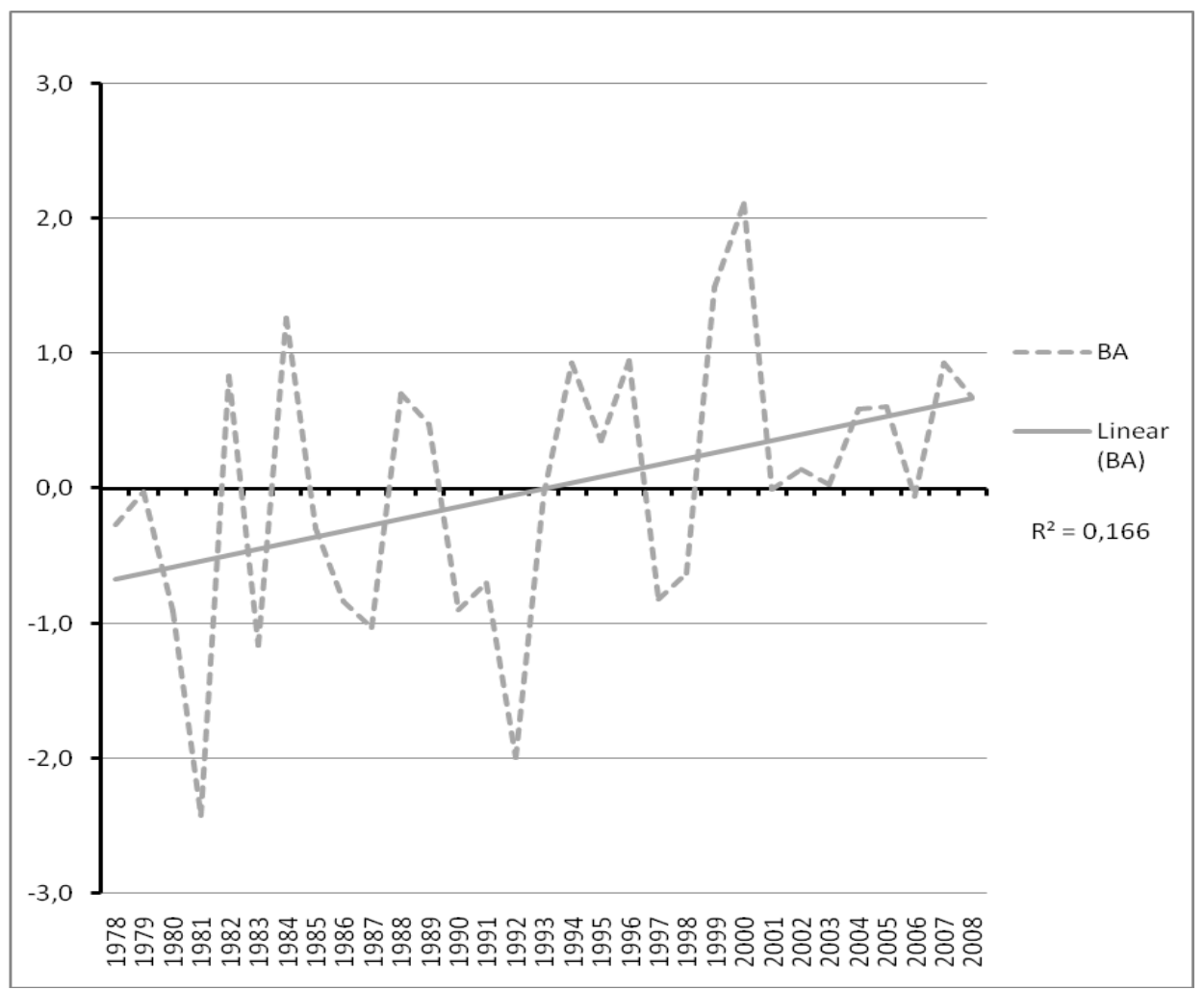

Figura 11. Séries temporais da anomalia d e precipitação padronizada sazonal para MAM (outono) nas mesorregiões do Pará. Unidade: desvio padrão.

\subsubsection{Trimestre JJA (Inverno)}

No trimestre de JJA (inverno) é a estação mais seca do estado, pois a ZCIT desloca-se para o HN, levando as fortes atividades convectivas para aquelas regiões. Nota-se que as mesorregiões do Marajó, Baixo Amazonas, Metropolitana e Nordeste apresentam comportamento e valores similares durante toda a série de dados, entre $200 \mathrm{~mm}$ até aproximadamente $600 \mathrm{~mm}$. Já as mesorregiões Sudeste e Sudoeste do estado apresentam os menores valores entre todas as mesorregiões, com precipitação abaixo de $200 \mathrm{~mm}$, isso se dá ao fato da baixa ocorrência de sistemas frontais. Nota-se que nos anos de 1989, 1994, 1996, 2001 e 2005 encontram-se os maiores índices de precipitação da série de precipitação para o outono. Em 1997 nota-se o menor índice pluviométrico da série, para todas as mesorregiões do estado, provavelmente esse baixo índice de precipitação está relacionado ao episódio de forte El Niño observado neste ano.

$\mathrm{Na}$ analise das mesorregiões para o inverno nota-se que a mesorregião do Nordeste apresenta altos índices de anomalias positivas até 1991, após percebe-se anomalias de precipitação muito negativa até o final da série. Notase que a mesorregião do Nordeste apresenta tendência negativa de chuva sazonal de inverno, com $\mathrm{R}^{2}=0,053$. 


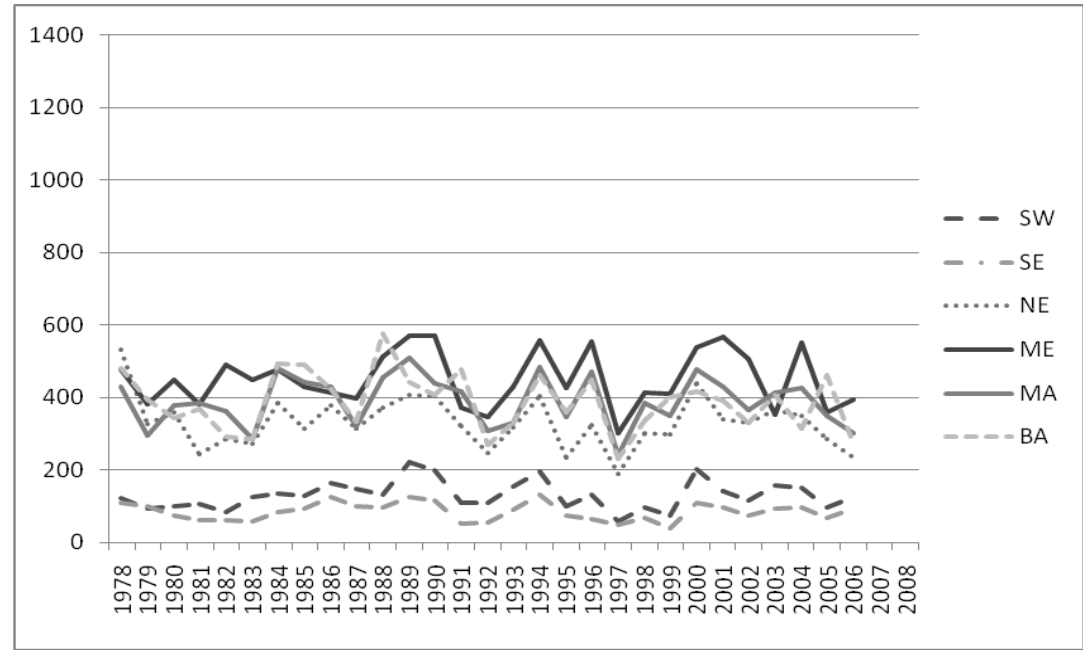

Figura 12. Séries temporais da precipitação total sazonal para JJA (inverno) nas mesorregiões do Pará. Unidade: mm.

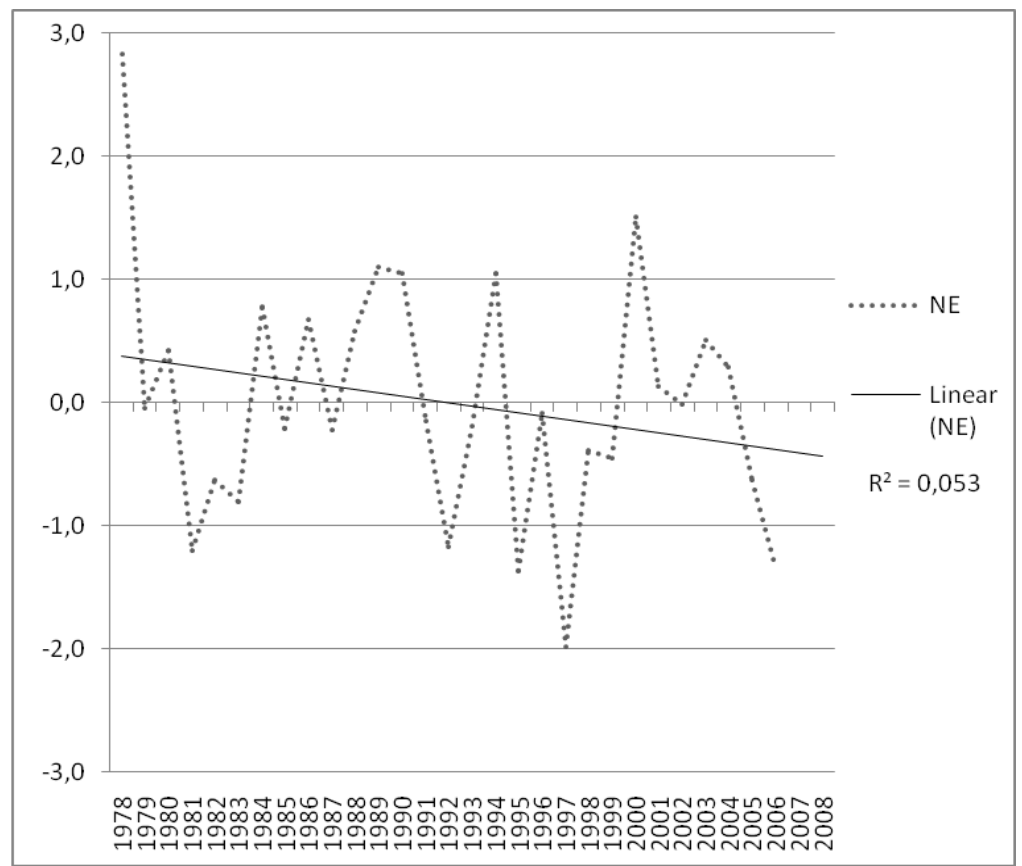

Figura 13. Séries temporais da anomalia de precipitação padronizada sazonal para JJA (inverno) nas mesorregiões do Pará. Unidade: desvio padrão.

\subsubsection{Trimestre SON (Primavera)}

$\mathrm{Na}$ figura 14 observamos que as mesorregiões Sudeste e Sudoeste apresentam os maiores índices de precipitação, isso se dá pelo início da atividade convectiva associada à ZCAS, iniciando nestas áreas o ciclo de chuvas. Existem situações em que o comportamento médio é influenciado por outros fatores que provocam um desequilíbrio atmosférico alterando a distribuição espacial e temporal da precipitação. 


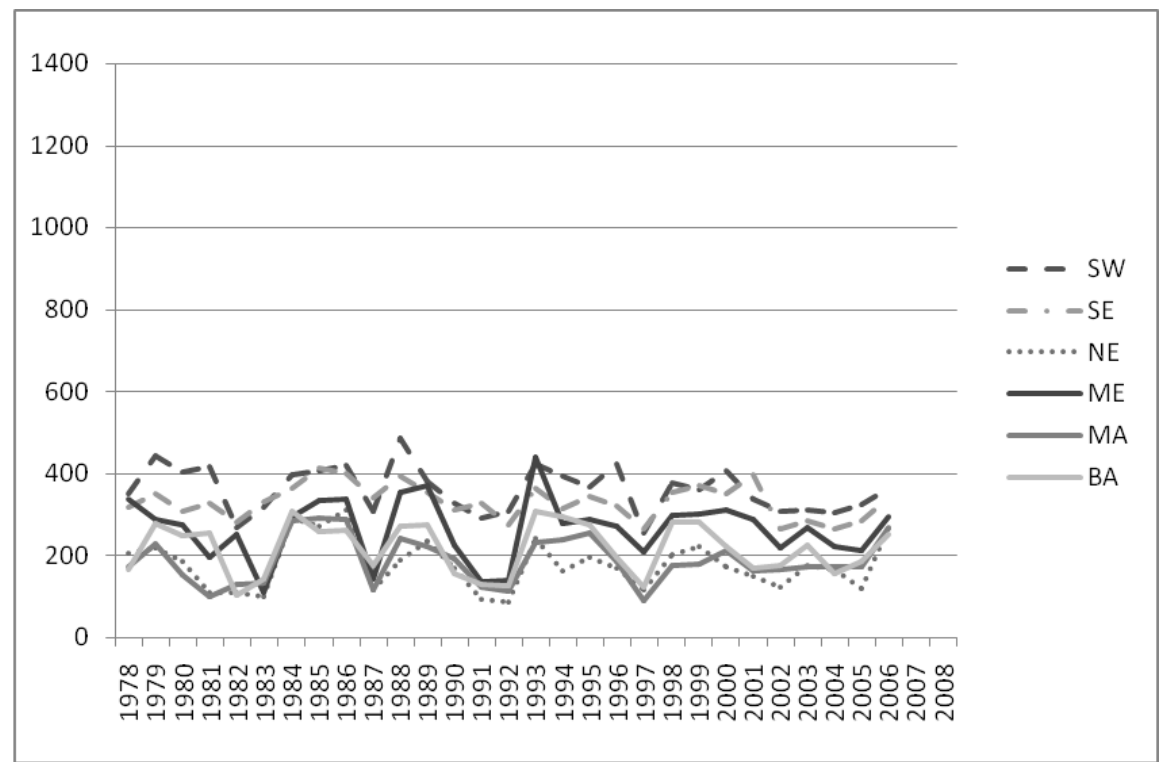

Figura 14. Séries temporais da precipitação total sazonal para SON (primavera) nas mesorregiões do Pará. Unidade: $\mathrm{mm}$.

A partir da analise das mesorregiões observou-se que a mesorregião Sudoeste paraense foi a que apresentou mais acentuada tendência negativa de precipitação sazonal de primavera, com $\mathrm{R}^{2}=0,084$. Na figura 15 notou-se que as anomalias positivas são observadas de 1978 a 1992 e anomalias negativas a partir de 1993, permanecendo assim até o final da série de dados.

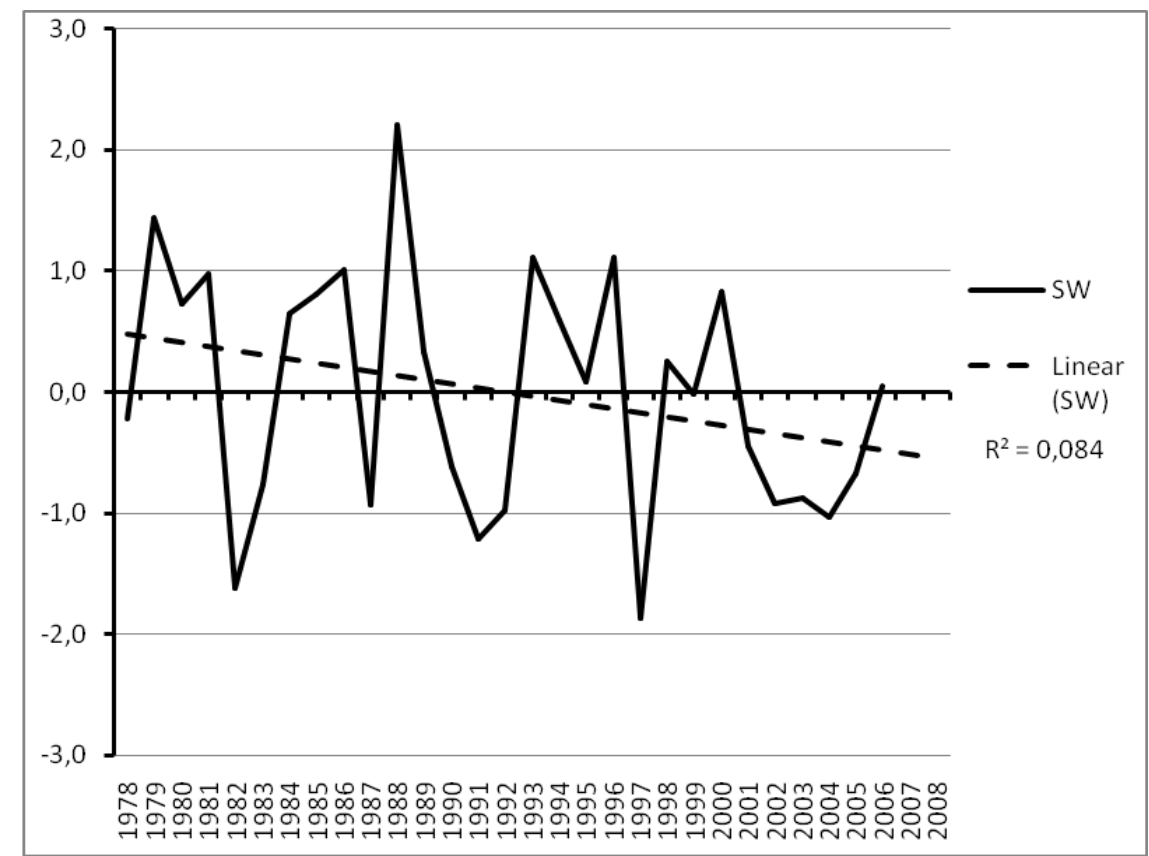

Figura 15. Séries temporais da anomalia de precipitação padronizada sazonal para SON (primavera) nas mesorregiões do Pará. Unidade: desvio padrão. 


\section{CONCLUSÕES}

O objetivo principal deste trabalho foi estudar a climatologia, tendência e a variabilidade da precipitação observada nas mesorregiões do Estado do Pará nas últimas décadas (1978-2008). Através de dados de precipitação do banco de dados do projeto Rede Estadual de Previsão Climática e Hidrometeorologica do Pará (RPCH), observou-se que a partir da distribuição média anual da precipitação, os maiores índices estão concentrados no Nordeste paraense. Com relação à evolução da chuva sazonal, verifica-se em todas as mesorregiões a ocorrência de uma transição muito brusca do período chuvoso para o período seco, com diminuição drástica dos valores de precipitação. Evidenciou-se que o ciclo anual da precipitação no Estado é fortemente modulado pela marcha da ZCIT, causando os trimestres mais chuvosos de março, abril, maio (MAM) e dezembro, janeiro, fevereiro (DJF); e os menos chuvosos de setembro, outubro, novembro (SON) e junho, julho, agosto (JJA).

$\mathrm{Na}$ analise das séries temporais da anomalia de precipitação padronizada anual, observou-se que os desvios de anomalia para as mesorregiões do estado, foram positivos até o final da década de 90, com elevados índices de precipitação para as mesorregiões Sudeste e Sudoeste do Estado. Por outro lado, após o ano de 1993/1994 os desvios de anomalias tornaram-se negativos, com anomalias muito negativas para a mesorregião do Sudeste do estado, ao contrario da mesorregião Nordeste do estado que apresentou anomalia negativa muito pequena.

Há uma tendência negativa (diminuição) de chuva sazonal do verão principalmente para as mesorregiões Sudeste e Sudoeste. Inversamente, notase uma ligeira tendência positiva (aumento) de chuva sazonal de verão para a mesorregião do Baixo Amazonas. Uma ligeira tendência positiva de chuva sazonal de inverno também é verificada para a mesorregião do Sudoeste, enquanto que as mesorregiões do Baixo Amazonas Nordeste apresentam tendência negativa. Em geral, nota-se uma tendência positiva generalizada de chuva sazonal de outono para todas as mesorregiões do Pará. Já a chuva sazonal de primavera nota-se claramente a tendência negativa nas mesorregiões Sudeste e Sudoeste Paraense.

\section{REFERÊNCIAS BIBLIOGRÁFICAS.}

CAVALCANTI, I.F.A; KOUSKY, V.E Influências de circulações de escala sinótica na circulação de brisa marítima na costa norte-nordeste da América do Sul. São José dos Campos, INPE, 1982. (INPE-2573-TDL/097)

COHEN, J. C. P. Um estudo observacional de linhas de instabilidades na Amazônia. 1989. 174f. Dissertação (Mestrado em Meteorologia) - Instituto Nacional de Pesquisas Espaciais, INPE, São Paulo, 1989.

FIGUEROA, S. N.; NOBRE, C. A. Precipitations distribution over Central and Western Tropical South América. Climanálise. Boletim de Monitoramento e Análise Climática, v.5, n. 6, p. 36-45. 1990.

FISCH, G.; MARENGO, J. M.; NOBRE, C. A. Uma revisão geral sobre o clima da Amazônia. Acta Amazônica, v.28, n.2, p.101-126. 1998. 
INSTITUTO BRASILEIRO DE GEOGRAFIA E ESTATÍSTICA - IBGE Divisão Regional do Brasil em mesorregiões e microrregiões geográficas. Rio de Janeiro, 1990. v.1.

KOUSKY, V.E.; KAYANO, M.T. A climatological study of the tropospheric circulation over the Amazon region. Acta Amazonica, v. 11, p. 743-758. 1981.

KOUSKY, V.E.; FERREIRA, N.J. Interdiurnal surface pressure variation in Brazil: Their spatial distribution, origins and effects. Monthly Weather Review, n. 109, p. 1999-2008. 1981.

KOUSKY, V. E.; CAVALCANTI, I. F. A.; GAN, M. A. Contrasts between wet and dry periods within the 1981 rainy season in Northeast Brazil. In: International conference on Southern Hemisphere Meteorology 1., 1983, Sao Jose dos Campos, SP. 1983. (INPE-2728-PRE/310).

LOPES, M. N. G. Aspectos regionais da variabilidade de precipitação no Estado do Pará: estudo observacional e modelagem climática em alta resolução. 2009117 f. Dissertação (Mestrado em Ciências Ambientais) Universidade Federal do Pará (UFPA), Belém.

MOLION, L. C. B. Climatologia dinâmica da Região Amazônica: mecanismos de precipitação. Revista Brasileira de Meteorologia, v.2, p.107-117. 1987.

MOLION, L. C. B. Amazonian rainfall and It's variability. Hydrology and water management in the humid tropics. Cambridge: Cambridge University Press, 1993. p.99-111.

MOLION, L.C.B; KOUSKY, V.E Climatologia dinâmica da troposfera sobre uma tropical da Amazônia. INPE-3560-RPE/480, São José dos Campos, São Paulo, Brazil, 1985. INPE-3560-RPE/480, São José dos Campos, São Paulo, Brasil, 1985.

OLIVEIRA, A.S. Interações entre Sistemas Frontais e a atividade convectiva na Amazônia. 1986. Dissertação (MSc. em Meteorologia) - INPE, São José dos Campos, 1986.

ROCHA, E.J.P. Balanço de umidade na Amazônia durante o experimento FLUAMAZON. 1991. Dissertação (MSc. em Meteorologia) - Departamento de Ciências Atmosféricas-IAG-USP, São Paulo, 1991.

SOUZA, E. B.; AMBRIZZI, T. Pentad precipitation climatology over Brazil and the associated atmospheric mechanisms. Climanálise, São José dos Campos, v. 5, n.6 p. 36-44. jan. 2003.

VIRJI, H. ; KOUSKY, V. E. Regional and Global Aspects of a Low Latitude Frontal Penetration in Amazonas and Associated Tropical Activity, São José dos Campos-SP, Anais do First International Conference on Southern Hemisphere Meteorology, American Meteorological Society, 1983 